\title{
Orchestration Roles to Facilitate Networked Innovation in a Healthcare Ecosystem
}

\author{
Minna Pikkarainen, Mari Ervasti, \\ Pia Hurmelinna-Laukkanen, and Satu Nätti
}

\author{
"I'm so excited, we have needs and you have found") \\ solutions to them. There is nothing better than that.
}

Medical Doctor at the Nordic Hospital

(Interviewed for this study)

\begin{abstract}
This study examines orchestration roles in a networked innovation context characterized by significant transformation. In particular, an exploratory case study approach is taken to study the roles of innovation network orchestrators and their actions to facilitate networked activities in different phases of the innovation process. The context of the case study, a healthcare ecosystem that aims to co-create technological innovations to support the pediatric surgery journey, provides valuable insights about orchestration and adds knowledge on specific limitations set by the orchestrator-specific and context-related issues in a professional context. The findings of this study highlight the need for careful coordination that allows shared understanding of the goals of the orchestration process and achievable innovation implementations. It is shown that parallel, evolving, and even changing orchestrator roles are needed in complex networked innovation settings.
\end{abstract}

\section{Introduction}

The healthcare sector is currently facing a dramatic change brought about by the digitalization of services, more effective and cost-efficient care models, and selfcare promoting personalized healthcare (Caulfield \& Donnelly, 2013). Increased costs and the promise of connected health technologies have created a need for innovations that increase patient satisfaction. This need for new technological innovations has also created new business opportunities for companies that target the medical market. A company's success often depends on collaboration with other actors that influence the creation and delivery of their innovative technology solution (Valkokari et al., 2012). This dependency is particularly relevant in the healthcare context, where knowledge and resources need to be continuously distributed between different actors - such as doctors, nurses, patients, and companies - who have their specific features and motivations that need to be acknowledged. Networked innovation (i.e., negotiation in an ongoing purposeful communication and communicative process that relies on either a market or hierarchical mechanism of control; Swan \& Scarbrough, 2005) is needed. Then, it is not always the central stakeholders that can do the best job in combining all the different elements and managing the context-related complexities, but different intermediaries may be needed for the coordination task.

There is an ongoing debate in the literature about the best collaboration models and their management in network and ecosystem contexts (see Andersson et al., 2007; Möller \& Rajala, 2007; Tsujimoto et al., 2017; Valkokari, 2009; Wilkinson \& Young, 2002). Although valuable new research insights have been introduced (see Dhanaraj \& Parkhe, 2006; Järvensivu \& Moller, 2009; Möller \& Rajala, 2007; Valkokari, 2009), conceptual confusion still exists. Particularly, more detailed analysis is required on how to facilitate the innovation process in mutually beneficial collaboration, and how the collaboration practices evolve in different phases of the innovation process (e.g., Valkokari, 2012).

Innovation network orchestration can be characterized as a purposeful action or practice by an orchestrator (an actor such as a hub firm) to initiate and manage knowledge in the innovation process in networks and ecosystems (Nambisan \& Sawhney, 2011). Orchestration comprises a set of activities, and when an orchestrator 


\title{
Orchestration Roles to Facilitate Networked Innovation in a Healthcare Ecosystem
}

\author{
Minna Pikkarainen, Mari Ervasti, Pia Hurmelinna-Laukkanen, and Satu Nätti
}

conducts (some of) these activities in a specific manner (e.g., by exerting more or less power on other network or ecosystem members), it can be considered that the orchestrator takes a specific role. Over time, in a complex network or ecosystem, there can be multiple orchestrators taking a variety of roles.

In the existing literature, there are plenty of studies that focus on different innovation environments and orchestration activities (e.g., Dhanaraj \& Parkhe, 2006; Nambisan \& Sawhney, 2011). Some of them have focused on innovation management, whereas others place greater emphasis on network orchestration. Most of the literature on network orchestration is developed for large networks with a dominant hub firm (Gausdal \& Nilsen, 2011). Also, research (e.g., Gausdal \& Nilsen, 2011) has emerged on orchestration in smaller, innovative networks small and medium-sized enterprises (SMEs). Relatedly, a stream of literature has emerged on co-creation practices (Frow et al., 2016), including studies in the field of healthcare or service ecosystems specifically. Additionally, various marketing and business perspectives on customer-dominant logic and customer participation in value co-creation have been introduced (Grönroos \& Ravald, 2011; Vargo \& Lusch, 2004). However, research addressing the roles of the orchestrator, and the ways their practices evolve over the time in innovation processes, is still limited. Furthermore, contextual issues influencing orchestration in ecosystems are not yet completely understood. The empirical setting of this article, a healthcare ecosystem comprising hospital management, doctors, patients, and companies, for example, offers a great opportunity to gain deeper understanding of orchestration.

In practice, there are a number of activities in innovation networks that need to be carried out in order to facilitate innovation. This is particularly true in the healthcare domain (Black \& Gallan, 2015). Some advanced hospitals have already realized that joint innovation activity with companies could be the way to boost rapid advancements for the novel digital hospitals and home care solutions. Some of them have even started to create support facilities to help firms to take their places in innovation ecosystems. Similarly, firms can see value in accessing knowledge residing within a hospital environment. However, contextual issues may create challenges starting from the question of which actor(s) can act as orchestrator(s) to the issue of what kind of roles can and should be taken to achieve the best results.
In this article, an examination of the existing literature and empirical evidence from a healthcare ecosystem forms the basis for finding out: i) what kind of roles the orchestrator can have to facilitate collaboration and knowledge utilization in different phases of innovation process and ii) how the high-level professionalism as a contextual issue within healthcare ecosystems influences facilitative orchestration. We consider this issue through an exploratory approach, starting from existing research and then examining a specific network that aims to create technological innovations to support the pediatric patient journey from home to hospital and back home: the Nordic Hospital in Finland is one example of advanced hospitals promoting ecosystem thinking. It has a test lab and a specific model for innovation management in its own premises. The test lab, together with the contribution of healthcare professionals, is used to support continuous innovation among health professionals, large companies, and SMEs. Considering the variety of involved actors, we begin the empirical examination by identifying the orchestrators in the innovation ecosystem. We then proceed to examine the roles and their adoption. Finally, we discuss the results and offer concluding remarks.

\section{Roles and Practices in Innovation Network Orchestration}

Managing any innovation process is a multifaceted task. In the environment in which there is a high diversity of partners and their contributions, that is, in innovation networks and ecosystems, an orchestrator is needed who will secure valuable inputs and mitigate concerns from network actors (Dhanaraj \& Parkhe, 2006). Different network roles - which refer to the orchestrator doing specific orchestration activities in a specific way - can be found in the existing research. Network-orchestration activities include ensuring knowledge mobility, network stability, and innovation appropriability, as well as coordination, agenda setting, and mobilization (see, e.g., Dhanaraj \& Parkhe, 2006; Hurmelinna-Laukkanen et al., 2014; Nambisan \& Sawhney, 2011; Roijakkers et al., 2013). In different roles, these activities can be emphasized to different extents (e.g., highlighting knowledge mobility over appropriability or vice versa) and can be carried out in quite different ways (e.g., by exerting control over others or by simply facilitating different activities). Multiple network members may participate in these activities, but the responsibility lies with orchestrators. In many cases, the type of the orchestrator and the innovation 


\title{
Orchestration Roles to Facilitate Networked Innovation in a Healthcare Ecosystem
}

\author{
Minna Pikkarainen, Mari Ervasti, Pia Hurmelinna-Laukkanen, and Satu Nätti
}

network or ecosystem are decisive for the emergence of specific roles. Acknowledging the orchestrator roles is therefore relevant.

\section{Different types of orchestrators}

Earlier research suggests that the so-called player orchestrators and non-players (Roijakkers et al., 2013) have different approaches toward orchestration activities, and different means to conduct them. A player orchestrator typically is an actor that has relatively strong individual incentives within the networks and ecosystems that it aims to influence, such as a company that competes with other actors in the end markets. Correspondingly, a non-player orchestrator influences and supports the network without being an active competitor in the end market (Leten et al., 2013; Roijakkers et al., 2013). These non-players can be further divided into facilitators and sponsors. The latter type of orchestrators have their individual goals coupled with collective goals (consider, for example, venture capitalists and business incubators; Comacchio et al., 2012; Napier et al., 2012), whereas the facilitators' main concern is the wellbeing and functioning of the network: they are not as interested in utilizing the innovation outcomes themselves, nor are they orchestrating the networks for financial gain (see Fichter, 2009; Hurmelinna-Laukkanen \& Nätti, 2012; Metcalfe, 2010).

All of these types could well emerge in health ecosystems. However, when individual professionals are in a central role - such as doctors in a health ecosystem - it could be assumed that large companies might not be the first ones to become orchestrators. Player-orchestrators of this kind might not be able to incorporate the strong professionalism from the side of doctors and other healthcare experts. On the other hand, smaller firms might lack resources, and health care professionals might neglect the business aspects. A neutral intermediary might be able to step in as a facilitator-orchestrator, and bring the diverging actors together. Thus, the focus of this study stays with facilitative orchestration and the related roles.

\section{Variety in orchestration roles}

The mentioned orchestrator types resonate with the ways in which they conduct orchestration activities. Players, for example, likely take more control and use their resources to persuade other actors (HurmelinnaLaukkanen et al., 2014). Furthermore, different activities may become differently emphasized depending on, for example, the phase of the joint activities. Aspects related to network formation, such as mobilization, become highlighted at times, while network management issues, such as ensuring knowledge mobility, are more pronounced at others (Brown \& Duguid, 2001; Ritala et al., 2012), for example. Accordingly, orchestrators adopt different roles.

The existing literature provides some specific examples, as shown in Table 1. For instance, the architect role emphasizes relatively strict agenda setting and coordination activities, run mainly by player-orchestrators (Hurmelinna-Laukkanen et al., 2014; see also Nambisan \& Sawhney, 2011). A similar, relatively controlling approach is present in the roles of gatekeeper (Czakon \& Klimas, 2014; Howells, 2006), conductor (Nambisan \& Sawhney, 2011) and judge (Hinterhuber, 2002; Howells, 2006), where the benefit of a player-orchestrator trying to strengthen its own competence is highlighted even if the individual orchestration activities are emphasized to different extents (see Table 1).

Table 1. Orchestration roles and their key activities

\begin{tabular}{lll}
\hline Role & Key Activities & References \\
\hline Architect & Engage in strict agenda-setting and coordination activities & $\begin{array}{l}\text { Hurmelinna-Laukkanen et al., 2014; } \\
\text { Nambisan \& Sawhney, 2011 }\end{array}$ \\
\hline Gatekeeper & $\begin{array}{l}\text { Support the knowledge extraction and dissemination of the } \\
\text { information }\end{array}$ & $\begin{array}{l}\text { Czakon \& Klimas, 2014; Howells, } \\
\text { 2006 }\end{array}$ \\
\hline Conductor & Take care of information acquisition, transmission, and task sharing & Nambisan \& Sawhney, 2011 \\
\hline Developer & Create concrete assets for the network based on knowledge mobility & Hinterhuber, 2002 \\
\hline Auctioneer & Set the agenda and joint vision for the innovation network & Wallin, 2006 \\
\hline Leader & $\begin{array}{l}\text { Motivate and foster the voluntary collaboration and identifying roles } \\
\text { of network members }\end{array}$ & Dawson et al., 2014 \\
\hline Promoter & Support ecosystem members to work towards the same goal & Dawson et al., 2014 \\
\hline Facilitator & $\begin{array}{l}\text { Bring together quite different, even competing, parties to work } \\
\text { together }\end{array}$ & Hurmelinna-Laukkanen et al., 2014 \\
\hline
\end{tabular}

www.timreview.ca 


\section{Orchestration Roles to Facilitate Networked Innovation in a Healthcare Ecosystem}

Minna Pikkarainen, Mari Ervasti, Pia Hurmelinna-Laukkanen, and Satu Nätti

Requiring a somewhat more relaxed approach (and therefore quite suitable and natural for sponsor-orchestrators) in representative roles, orchestrators share knowledge of the network with "outsiders". This is quite similar to a liaison role. In these roles, the activities are more supportive, even if network formation and management activities are in the focus such as in the roles taken by players. Sponsor-orchestrators are also the most likely ones to take coordinator and developer roles (Hinterhuber, 2002) or an auctioneer role (Wallin, 2006).

In the least controlling group of roles, a leader role is characterized by a goal of motivating and fostering the voluntary collaboration. A good leader (typically a facilitator-orchestrator) is knowledgeable and passionate about the topic. The primary role is to link people, skills, and needs together (see Gausdal \& Nilsen, 2011). A promoter role (see, e.g., Dawson et al., 2014) falls quite naturally to facilitators that should be able to bring together quite different, even competing, parties (Hurmelinna-Laukkanen et al., 2014). Discussions on the community leadership and leadership processes that cover, for example, informally linking community members, and fostering development of community members (see, e.g., Gusdal \& Nilsen, 2011; Keeble \& Wikinson, 2000; Wenger et al., 2002) reflect this.

Although earlier literature indicates that these different roles are relevant from an orchestration point of view, there is relatively little written on what happens over time, and what kind of constraints and enabling determinants (also beyond the orchestrator type, see Hurmelinna-Laukkanen et al., 2014) may be related to having specific roles in different contexts. Therefore, in this study, we set out to empirically examine an ecosystem in the healthcare sector that aims to co-create technological innovations with various stakeholders.

\section{Research Design}

The method chosen for this study is an explorative, indepth single case study (e.g., Lazar et al., 2010). We suggest that this approach is appropriate because more indepth understanding of orchestration itself - and understanding of multi-sided contextual influences - are needed (Yin, 2003). Abductive research logic is used, where theoretical and empirical material is considered side by side (Kovács \& Spens, 2005).

\section{Research context}

Our case study builds on data collection from an 18month period at the Nordic Hospital. The case study was conducted as a part of a larger research project, where various actors came together with an aim to create technological innovations to support the pediatric surgery journey from a patient's home to hospital and back home. Such a project forms an excellent context to study orchestration, as the hospital environment represents a high-level expert context where orchestration can be extremely challenging due to strong professionalism, diverging priorities of actors, strict regulations, and ethical constraints. Furthermore, agendas and motivations may change at different stages of the innovation process, with the involvement level of different actors fluctuating as the innovation activities proceed.

This study was conducted within a research project that aimed to support network orchestration to create new solutions for future hospital programs and was a part of the Nordic innovation ecosystem. The studied ecosystem aims for efficient returns on investment and, most importantly, for the creation of jobs in the healthcare sector. This healthcare ecosystem comprises several stakeholders from academia, the public sector, and the private sector. In this context, the Nordic healthcare innovation environment, the hospital's test lab environment, and the research project's representatives became natural targets of analysis as orchestrators. At the premises of the Nordic hospital's testing and innovation environment, new services can be demonstrated and evaluated in an authentic hospital environment together with genuine end users: citizens and health professionals.

Thus, in this study, the unit of analysis is the network orchestrator within the context of the Nordic ecosystem, specifically in the case of the pediatric surgery journey. The target of the orchestrator in this context was to facilitate the co-creation of innovations that support patients and health professionals in future hospital environments. In particular, the focus in the examined case was to gain deep understanding of the care-taking process and real end-user needs, as well as to ideate new solutions for pediatric surgery patients, including children who require surgical treatment with anesthesia provided by secondary healthcare. The other aim was to ideate new innovations to support the work of doctors and nurses that work in the pediatrics surgery department and to ease working with the day surgeries that represent $40 \%$ of the acute emergency operations. Furthermore, we investigated differences in willingness and motivation among end users in relation to their participation in the co-creation innovation process. 


\section{Orchestration Roles to Facilitate Networked Innovation in a Healthcare Ecosystem}

Minna Pikkarainen, Mari Ervasti, Pia Hurmelinna-Laukkanen, and Satu Nätti

The research project also resulted in a digital co-creation platform to help startup companies and SMEs integrate easily into the hospital systems. The goal was to speed up the co-design of future hospital services together with doctors, nurses, patients, and large companies, and thereby facilitate the adoption of innovations in hospitals. Figure 1 below illustrates the innovation ecosystem in the examined healthcare sector.

The project revolved around the co-creation of innovative products and services built together with SMEs, large companies, and end users (i.e., doctors, nurses, and parents of child patients). This innovation process was aided by the network orchestrators (i.e., the research and business incubator organizations and the test lab personnel). Pediatric specialists, nurses, parents of child patients, innovation orchestration management, large companies, and startups were involved in the data collection activities detailed in next Section. As a result, a comprehensive view of the case was obtained.

\section{Data collection and analysis}

In our case, an extensive user study was conducted in the form of interviews with healthcare professionals, the parents of child patients, companies; workshops; online discussions; and research meetings in which the representatives from the research and business incubator organizations in the project participated both as organizers and external observers (Table 2).
Experience-based design (EBD) (cf. Bate \& Robert, 2006) was used as a method for co-designing novel hospital services together with patients and healthcare professionals based on their actual experiences of health services. The use of the EBD approach ensured that ideated children hospital services truly reflected the needs of patients, carers, and healthcare professionals based on their specific experience. Flowcharts of patient journey maps were used as a platform upon which experiences could be collected. Patient journey maps helped to define the pediatric surgery process as a chronological entity (i.e., what happens in each phase of the process) and view it from the family's perspective, as well as to identify and understand the roles and tasks of the health professionals in different phases along the surgery process, and how the different stakeholders communicate with each other.

In the workshops, current actions and challenges were identified in each surgery process phase from the perspectives of all three end-user groups by systematically going through the transcripts. Accordingly, improvement ideas and technological solutions were mapped throughout the process. Through the interviews, online discussions, and workshops, we gained a thorough understanding of the current practices and challenges from various points of view and how technology innovations could be utilized in future pediatric care journeys.

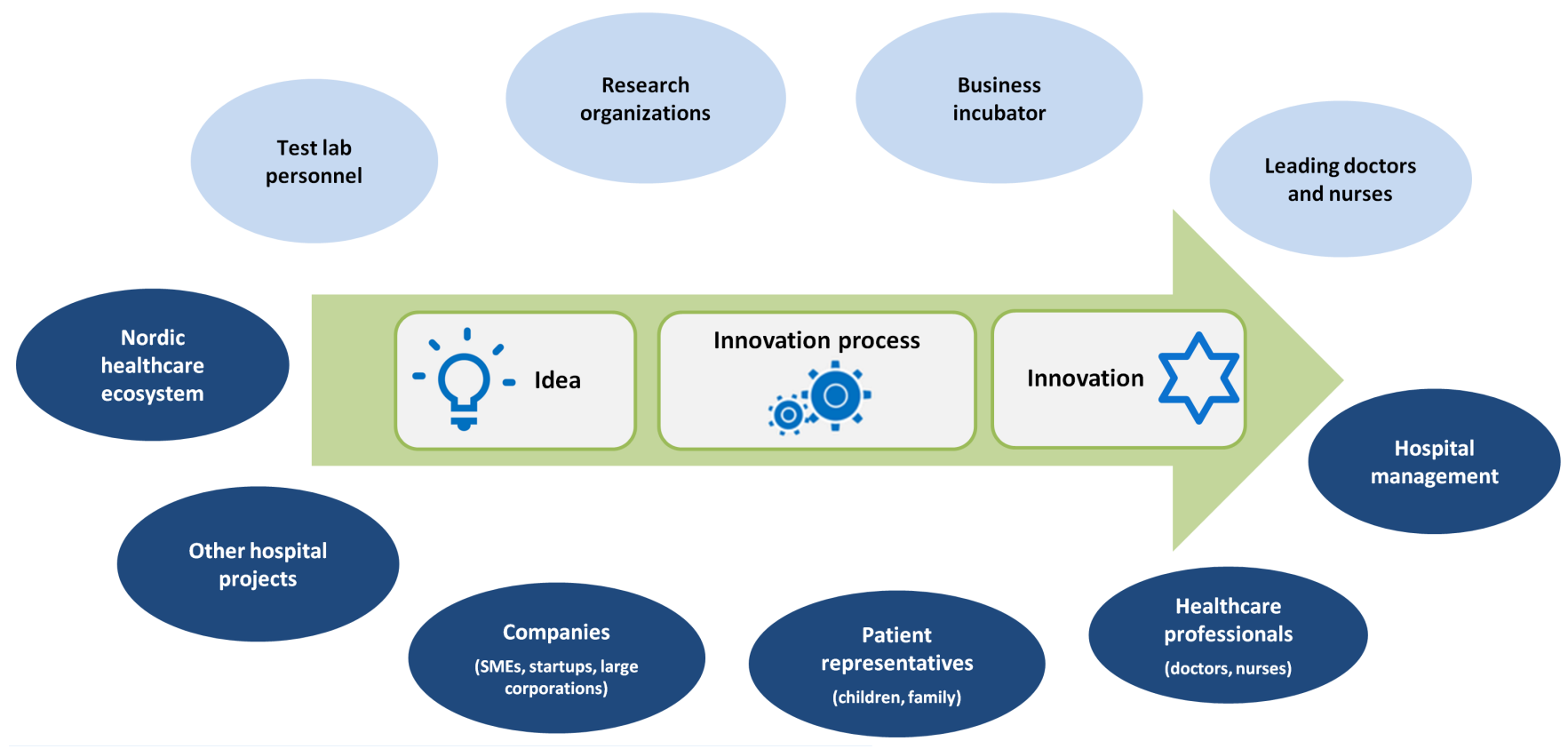

Figure 1. Healthcare innovation ecosystem related to the pediatric surgery case 


\title{
Orchestration Roles to Facilitate Networked Innovation in a Healthcare Ecosystem
}

\author{
Minna Pikkarainen, Mari Ervasti, Pia Hurmelinna-Laukkanen, and Satu Nätti
}

Table 2. Summary of innovation orchestration activities with parents of child patients as well as doctors, nurses, and companies

\begin{tabular}{lll}
\hline Innovation Orchestration Activity & Participants & Organizations \\
\hline Interviews with pediatric specialists & 7 doctors & Nordic Hospital \\
\hline 1st workshop with pediatric nurses & 2 nurses & Nordic Hospital \\
\hline 2nd workshop with pediatric nurses & 3 nurses & Nordic Hospital \\
\hline 3nd workshop with pediatric nurses & 4 nurses & Nordic Hospital \\
\hline Online discussion with parents of child patients & 6 parents & Nationwide \\
\hline Workshop with parents of child patients & 6 parents & Nordic Hospital \\
\hline 10 interviews with companies & 13 companies & 7 SMEs and 6 large corporations \\
\hline
\end{tabular}

\section{Results}

The healthcare innovation ecosystem as a context for orchestration

As suggested above, there are some specific issues in the healthcare ecosystem context that make it different from many other networked innovation ecosystems. In this study, the collected information soon revealed that there are tradition-based, implicitly and explicitly accepted strong professional hierarchies that cannot be overridden. In addition, in this context, there seems to be a need for awareness of various and often conflicting interests among core actors. These competing interests create the need for open and planned innovation network orchestration procedures through which they can be satisfactorily reconciled.

The examined orchestrator roles in the ecosystem were organized taking these features into account. The target, vision, and goal setting for the innovation activity in the pediatric surgery journey were first determined together with the hospital management, leading experts, and research organizations, and the business incubator organization of the project. Naturally, all these actors approached collaboration from different angles. The hospital representatives' aim and motivation to participate in the collaboration were to save costs and improve the overall patient experience through technological innovations. Thus, they invested considerable amounts of the health professionals' time and resources in the innovation co-creation: "This co-creation costs quite a lot for hospitals if we think about the work time of doctors and nurses; this demands quite a commitment from hospital management" (CEO of a company). Through this remarkable investment, hospital representatives wanted to build better technological innovations to improve their own efficiency and end-user satisfaction.

From the company perspective, cooperation with the hospital was something they had been looking for: the hospital can be seen as a potential customer. However, the innovation project setting presumed cooperation with other companies as well - even competitors, which was a surprise for many participating firms. The link to the innovation ecosystem that the hospital was offering also meant collaboration with other industrial players such as hospital system providers who are targeting their solutions to the same market. Additionally, the project included meetings and common occasions in which the participating companies had to show the solutions to the doctors, nurses, and parents of child patients in the presence of their competitors. These issues generated tensions in the innovation network. The companies considered the new role of the hospital in the innovation process both as beneficial and challenging from their own perspectives. For example, "I'm so excited, we have needs and you have found solutions to them. There is nothing better than that.", "we are in a better position with our solution compared to our competitors", and "we have received customer references that have a significant role when we are selling our solutions". The references gained from these aforementioned innovation activities were helpful later on, as the participating startup companies could get real sponsors such as venture capitalists to support their future innovation work. 


\title{
Orchestration Roles to Facilitate Networked Innovation in a Healthcare Ecosystem
}

\author{
Minna Pikkarainen, Mari Ervasti, Pia Hurmelinna-Laukkanen, and Satu Nätti
}

\section{Orchestrators in the healthcare ecosystem}

In our case, multiple parallel actors took part in forming and managing the networked innovation activity. Namely, the actors adopting the orchestrator roles in our case could be identified as: i) the test lab personnel at the hospital, ii) the project's research organizations, iii) the project's business incubator organization, and iv) leading experts at the hospital (e.g., doctors and nurses). The hospital assumed an important role and part of the responsibility for promoting the ecosystem. The hospital had, as mentioned above, a test lab organization where commercial actors could test their solutions in an authentic environment. The test lab personnel were initially hired by hospital management. In the test lab, there was one person who was leading the innovation activities with different companies and taking care of the agenda setting, information sharing, and end-user involvement from a resource perspective. This person was also keeping up continuous discussions with hospital management.

However, since the hospital did not have resources to carry out these activities alone, the other orchestrators of this project eventually came from research institutes and a business incubator organization, and we chose to examine their roles in particular. The research institutes provided to the project multidisciplinary research groups with expertise in several research areas, such as service co-creation, business models, and connected health services. Responsibilities and information sharing between these facilitator-orchestrators turned out to form a barrier for information sharing in the overall setting. Although regular meetings were organized, the teams were overloaded with their own tasks and worked too much in isolation, which created challenges. It was difficult to find orchestrators for innovation networks that would have the capabilities to take care of many perspectives, such as those of the experts (healthcare professionals), patient representatives (parents of child patients), and commercially oriented companies. Nevertheless, what eased the situation was that much of the network orchestration responsibility was divided between actors that indeed could be considered facilitator-orchestrators and did not have their own financial goals to guard, but who were rather concerned about making the network work more efficiently as an entity. These facilitators took on notable orchestration activities in specific ways.

\section{Adopting leader and gatekeeper roles}

The research organization assumed a leader role. In this role, they were motivating high-level experts and patient representatives to engage in voluntary coopera- tion at the hospital settings. Whereas the project coordinators were the orchestrators for the whole co-creation network - influencing knowledge transfer for their part -the leading doctors and nurses in the organization had a similar position at a smaller scale: they led their own innovation units. They also adopted a role that could be considered as a gatekeeper in the innovation process. In our case, the leading doctors and nurses were important orchestrators given that they were also fostering the collaboration and allocating tasks for network members. They acted as gatekeepers of the sub-units of the network and made concrete actions to help ecosystem coordinators. For instance, they participated in the generation and definition of the innovation orchestration goal, which was the co-creation of technological innovations for the pediatric surgery journey. They also informed other doctors and nurses about the plans and asked them to participate in the innovation work (i.e., the workshops and interviews) during their working time. According to one doctor, "it is important that the knowledge is shared and everyone could see what has been done in different phases of the innovation process".

The support provided by the leading doctors and nurses and the adoption of the above-mentioned roles allowed the orchestrators to reach one important step: that of proving that something is really proceeding in the innovation process. The leading doctors, in particular, stated that it is important to show concrete results for the health professionals in order to keep them committed. In addition, the professionals being able to influence the end result was found highly important: "It is good to involve doctors when there is something ready to show to them, but not too ready so that it would not be possible to change it". Stemming from this specific context, maintaining motivation and giving enough room for professionals to influence seem to be two important empirical notions here. The leading doctors considered it important that the innovation work would be integrated with the other established processes at the hospitals. Likewise, doctors and nurses need to have resources allocated to the innovation work as a part of their clinical work. Both these notions stem from the scarce resources and time that the healthcare professionals could allocate tor the innovation process.

These roles were not enough, however. The facilitator orchestrators (i.e., the business incubator, research organizations, and test lab personnel) felt, especially, that the concrete collaboration between companies and end users could be even more efficient. It seemed that the academic orchestrator in this case did not have enough 


\section{Orchestration Roles to Facilitate Networked Innovation in a Healthcare Ecosystem}

Minna Pikkarainen, Mari Ervasti, Pia Hurmelinna-Laukkanen, and Satu Nätti

authority in the leader role and thereby was not able to keep every organization thoroughly involved in the meetings. A dual-core formed by different orchestrators (i.e the test lab orchestrators, business incubator, and academic orchestrators, likewise professionals in their own subunits) could provide the solution to this challenge. In fact, the orchestrators retrospectively considered that one possible approach would have been to enforce closer integration with the hospital, which would have increased the power for the orchestrator (who needed to orchestrate high-level experts, such as doctors) to ask all the stakeholders to join the relevant innovation activities and prioritize the innovation orchestration work in their agendas.

\section{Emergence of coordinator, auctioneer, and promoter roles}

In our case, the research organizations and business incubator formed a facilitator-orchestrator entity that first worked in an auctioneer role. They took action in agreeing and setting a joint agenda and vision for the project together with the test lab representatives, hospital management, and leading doctors. Research organizations also adopted a coordinator role through organizing regular meetings between different players. The purpose was to support knowledge extraction and information sharing. This did not work very well because the core players seemed to emphasize different aspects, they prioritized their own track first, and the information was not shared as planned between the actors. This finding highlights the importance of diligent orchestration in this specific context, more specifically agreeing on collaboration approaches, common goals, as well as roles and responsibilities among the orchestrators.

The research organizations and the business incubator had to step into a promoter role with a purposeful action to make these ecosystem actors work towards the same goals. One example of the promoter results is a narrative in which the future pediatric surgery process was described from home to hospital and back home including the core needs and innovation ideas collected from experts and patient representatives. The company assets were mapped into the narrative and described in such a way that it was easily understood by medical doctors and parents of the sick children who were involved in the innovation network and it was easy to give continuous feedback about the company ideas in different events and online system. Due to the communication structure, both the companies and end users reported their satisfaction with the results achieved by the innovation activities "When we know the needs of health professionals, we can prioritize what is important" (Company representative involved in innovation orchestration).

\section{Taking a representative role}

One more role emerging in our case was that of a representative. Because the innovation process in the project was carried out as a part of the Nordic ecosystem, the ecosystem actors together engaged in many activities to share the results through different seminars, publications, and forums. This type of information sharing of the innovation network ecosystem to outsiders was continuously done by research and business incubator organizations, but these tasks were allocated also to the test lab personnel. Such activities were considered important because the publicity and feedback also affected the legitimacy of the activities that were carried out.

\section{Contextual determinants of role adoption}

Our case indicates that the roles taken by innovation orchestrators can be parallel and changing over time (Figure 2). The key finding of our study is that, in an innovation network involving expert organizations, multiple organizations can take even parallel orchestrator roles in a networked innovation context, and there might be different kinds of orchestration activities performed and roles taken by different actors in different phases of the innovation process. For instance, from the hospital perspective, the research organizations and the test lab organization together with hospital management worked in auctioneer, coordinator, and leader roles by setting the goals, hiring new people, and getting leading doctors and nurses involved as gatekeepers. The academic orchestrators took the promoter role by helping network actors establish ways to show the ideated technological innovations and concepts to the end users with the purpose of gaining valuable feedback and informing them about the success cases in which the innovations were co-created based on the needs of health professionals. Academic orchestrators together with business incubator orchestrators also worked as promoters by helping the hospital and companies identify the needs, set common goals, and organize the ways for companies to show the concepts to doctors, nurses, and patients. The Nordic ecosystem worked as a representative for organizing ecosystem seminars that helped inform about the project's success stories both outside and inside of the hospital. 


\section{Orchestration Roles to Facilitate Networked Innovation in a Healthcare Ecosystem}

Minna Pikkarainen, Mari Ervasti, Pia Hurmelinna-Laukkanen, and Satu Nätti

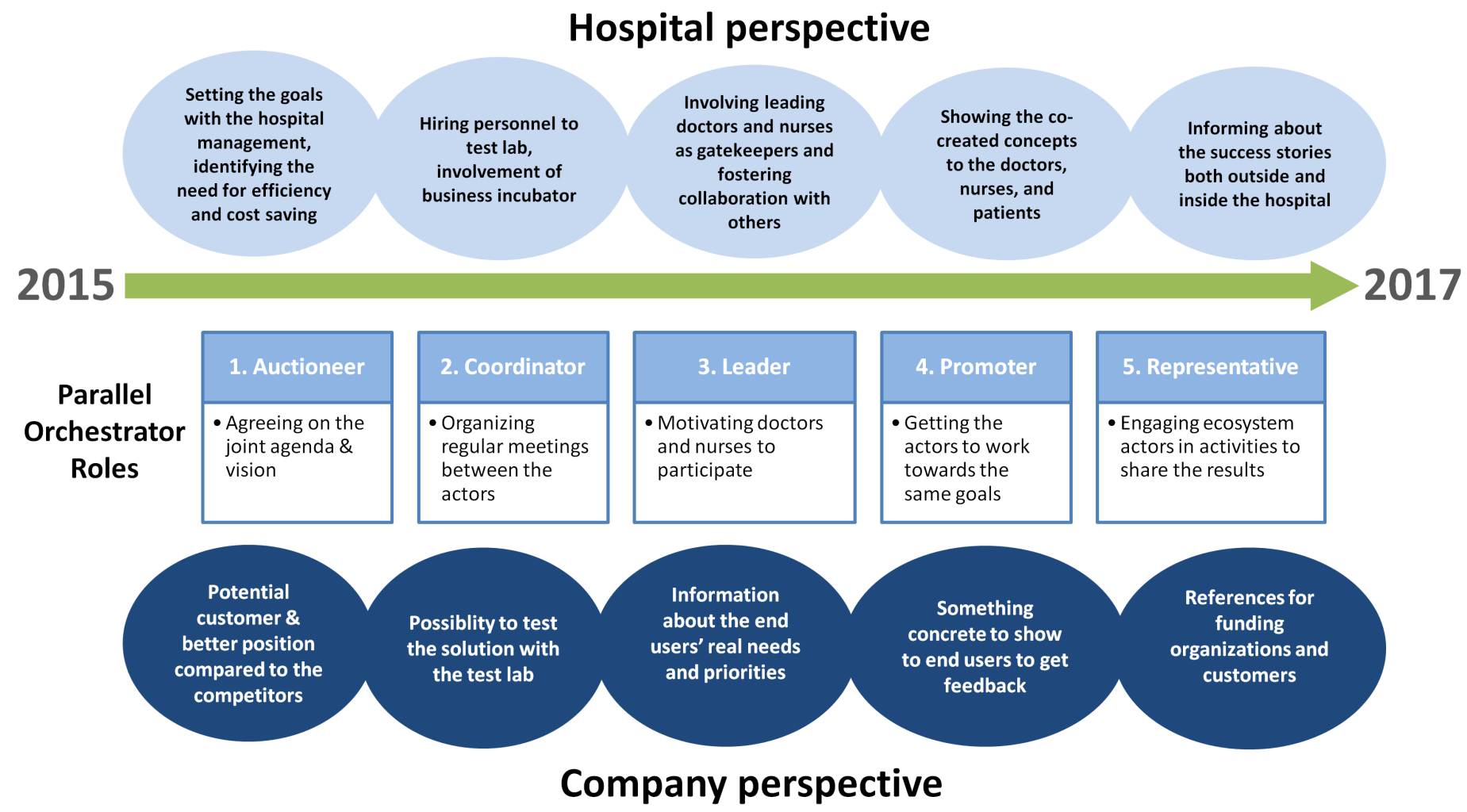

Figure 2. Innovation orchestration roles from different perspectives over time (2015-2017)

Participating companies saw the innovation actions as a potential to gain customers and concrete references as well as to better understand the real needs of end users (i.e., child patients and their families, and doctors and nurses in the pediatric surgery department). They received information about the end-user needs and priorities and had opportunities to show their solutions to the hospital staff and management and gain valuable feedback to develop their solutions further.

A key challenge of networked orchestration in the hospital context was the tradition-based hierarchical culture, which required extra efforts in developing and agreeing upon the joint agenda and vision. Likewise, motivating the actors to participate in the innovation activities was challenging, as the network that was to be orchestrated consisted of diverse actors. Sub-units existed with highly influential leaders (doctors) who were at the same time involved with other innovation networks orchestrated by other hospital project managers, for instance.

\section{Influence of orchestrator's roles}

Due to the resource situation at the hospital, additional orchestrators of this project eventually came from a re- search institute and a business incubator. However, the initially unclear responsibility allocation and activity identification caused a situation in which the research organization tried to carry out too many tasks in the ecosystem with limited influential power. The roles that the core orchestrators were able to adopt were restricted not only due to their own non-medical background, but also due to contextual issues including a more valued and stronger expertise of other actors, prevailing traditions, and also regulatory issues.

Because of the lacking medical background of the orchestrators, many healthcare professionals in the hospital were first suspicious about the capabilities of these new actors to orchestrate the innovation actions. Furthermore, the orchestrators in the health organizations had limited resources and time for innovation actions. It took time for the orchestrators to win the trust of the hospital management and involve gatekeepers (i.e., leading doctors and nurses) in the innovation process within this novel hospital context. Managing innovation coherence to gain mutual understanding and respect is extremely important in innovation networks working in a healthcare ecosystem in which the expert 


\title{
Orchestration Roles to Facilitate Networked Innovation in a Healthcare Ecosystem
}

\author{
Minna Pikkarainen, Mari Ervasti, Pia Hurmelinna-Laukkanen, and Satu Nätti
}

resources are limited and there are many players trying to orchestrate other parallel innovation networks with a goal of involving the very same health professionals.

The business incubator organization worked well in the regional settings, and given that their primary goal was to support companies' businesses, they naturally took the practical role of meeting the companies and discussing their business needs related to the project. Research organizations had a target to support the same companies in the innovation process by recruiting and involving end users and helping them to create ecosystemic business models to support innovation. At the same time, the hospital itself had new internal hospital development projects underway, which had targets of their own, such as to rapidly decide what services and technologies would be used in the new hospital settings. The conflicts appeared when the roles of the innovation orchestration were not discussed carefully between the orchestrators. Both research and business incubator organizations met the hospital management, other hospital development project leaders, companies, and health professionals from the same innovation ecosystem to better understand the different goal settings and methods to conduct innovation actions. Thus, in addition to understanding what should be done to advance innovation activities, it was important to understand how things should be done together.

Nevertheless, and somewhat surprisingly, these challenges faced by the orchestrators and the fuzziness in task allocation and limits of role taking did not become visible among the involved companies, patients, and health professionals. All these actors gave only positive feedback about the participation and end results of the innovation activities. One conclusion from this finding is that good orchestration also comprises the ability to keep the hardships at the orchestrator-level, and not let it disseminate to the ecosystem or contaminate individual relationships. From a company perspective, the influence of the orchestration activities was seen as a stronger position in the healthcare sector compared to their competitors, whereas, for high-level experts, the possibility to co-create better technological solutions to be used to solve their concrete work-related needs and challenges was intriguing and motivating. Judging from this outcome, intermediaries between hospitals and companies can be valuable in handling the context-related complexities and are needed for the coordination task. A neutral intermediary might be able to step in as a facilitator-orchestrator and bring the diverging actors together for the joint goal setting and vision, even when the roles that the orchestrators can adopt are limited.

\section{Discussion and Conclusions}

Transformational change evident in the healthcare sector drives the emergence of future hospital programs and digital innovations to tackle the need for improved staff productivity, hospital operations, overall patient experience, and high quality of care (e.g., Caulfield \& Donnelly, 2013). However, from a company perspective, the medical market is a challenging field for innovation. Hospitals are expert organizations having different systems that are not typically communicating between each other. Additionally, a large pool of other actors are offering similar or partially competitive solutions to same hospitals. Gaining access to and working together with end users, namely medical professionals and patient representatives, can be a challenging to even the largest, most established companies, not to mention the smaller firms.

The specific professional context of this study provides valuable insights about orchestrating within expert organization environments. Both theoretical and empirical research insights were derived from the analysis in this study. By focusing on the roles taken by orchestrators, that is, the specific orchestration activities (e.g., Dhanaraj \& Parkhe, 2006; Nambisan \& Sawhney, 2011) and the ways to conduct them (e.g., Czacon and Klimas, 2014; Hinterhuber, 2002; Howells, 2006; HurmelinnaLaukkanen et al., 2014; Ritala et al., 2012; Wallin, 2006) in a healthcare ecosystem, we were able to see how innovation network orchestrators, and more specifically facilitator-orchestrators (e.g., Comacchio et al., 2012; Napier et al., 2012) can take multiple, sometimes even parallel orchestrator roles in networked innovation. More specifically, we gained insights into how and in which limiting or facilitative conditions these roles are practically conducted.

Regarding the theoretical contribution, it became quite evident in our study that an orchestrator can take different roles over time in demanding contexts with a variety of diverging actors and regulatory and tradition-based restrictions. These parallel roles can create a democratic and collegial atmosphere for the ecosystem, which is needed to keep all the professional communities committed to the work, despite their high level of professional authority. Orchestration in this environment is definitely not about commanding, but about "discreet influence" (Ritala et al., 2012). We found support for the idea that the background and characteristics (e.g., the limited power position) of the orchestrator inherently limit the orchestrator actions (see, HurmelinnaLaukkanen et al., 2014) in this specific context: business 


\title{
Orchestration Roles to Facilitate Networked Innovation in a Healthcare Ecosystem
}

\author{
Minna Pikkarainen, Mari Ervasti, Pia Hurmelinna-Laukkanen, and Satu Nätti
}

incubator and research organization as facilitator-orchestrators were not seen to take roles of judges or architects for example, which (theoretically) fall to player-orchestrators (with stronger power positions) more naturally. Instead, they were taking more discrete coordinator tasks to keep all the actors committed. Second, restrictions to orchestration came from the context, such as rules and regulations related to the medical domain (see, e.g., Nambisan \& Sawhney, 2011 on a specific type of ecosystem for comparison), or the importance of professional hierarchy and related authority issues. Likewise, the challenge in such a multiactor environment is that all actors have their individual challenges, such as timing and resourcing challenges that had to be addressed, not to mention their different interests in participating in the collaboration in the first place.

From a managerial perspective, our study highlighted the importance of discreet influence needed when orchestrating a network of high-level experts and patient representatives within the specific network dynamics. For example, in this context, there are tradition-based, implicitly and explicitly accepted professional hierarchies one has to understand when orchestrating the network. In this case study, leading experts led their own innovation units and shared knowledge within professional communities and between them. From the orchestration perspective, this practice was functioning, for those professionals had professional authority needed to keep their units committed to the process. This helped ecosystem orchestrators considerably.

Our case study indicates - reflecting also the general lines in earlier studies (e.g., Dhanaraj \& Parkhe 2006; Möller, 2010; Ritala et al., 2012) - that there is a need to create a shared understanding of the roles in an innovation orchestration process, the development stage, the milestones to be pursued, and achievable innovation implementations. Expert ideas need to be continuously taken forward and implemented by the different actors in innovation ecosystem. But it is not only about harnessing ideas, it is also about giving feedback; throughout the innovation process, high-level experts must see concrete results from their work to keep them committed to the ecosystem. Professionals need to see that they have influenced the end result.

It might be impossible to find single orchestrators who possess understanding of all the perspectives, from end users to commercially motivated companies. Thus, cooperation is critical in forming the common understanding. However, combining a variety of perspectives for common goals and practices always brings along challenges for orchestration. Managing innovation coherence with interviews, workshop data, as well as with concluding narratives (where actors' assets are mapped to make the expertise explicit) was found as an important way to show hospital experts and firms how the company assets actually fit to the future pediatric surgery journey of children and their parents. This finding is in line with Nambisan and Sawhney (2011), who emphasized innovation coherence management as a way to manage innovation leverage. In general, supporting communication coherence related to end user needs and suitable company assets is important in innovation networks when working in health ecosystems. In health care organizations, the expert resources are often limited and there are many players trying to orchestrate the coinciding innovation networks by involving the same health professionals. In the context of high professionalism, a lack of coherency may generate selfishness based on diverging interests; every single actor may prioritize their own goals and tasks instead of common goal, hampering innovation efforts and causing a "vicious cycle of separation" among actors. This resource scarceness was seen as the need to integrate the innovation task into the everyday flow of work: in the ideal case, innovation activities are not something "separate", for the sake of innovation, but part of the normal work process. Finally, gaining legitimacy for innovation activities among different stakeholder groups is important.

Of course, our study comes with limitations. As an exploratory case study, the findings cannot be generalized too widely. Also, simplifying the complex setting likely reduces the richness of insight derived from the case. Nevertheless, together with our findings, these and other limitations provide opportunities for future research to find relevant avenues. For instance, the conflicts and contests emerging in the ecosystem and the opportunities to influence and solve these issues through the means of orchestration is a potentially interesting approach. Likewise, the interplay between the influencing actors at different levels seems to be a relevant research topic. Future studies can also achieve wider generalizability of our findings. This study can be used as the starting point. 


\section{Orchestration Roles to Facilitate Networked Innovation in a Healthcare Ecosystem}

\section{Minna Pikkarainen, Mari Ervasti, Pia Hurmelinna-Laukkanen, and Satu Nätti}

\section{About the Authors}

Minna Pikkarainen is a joint Connected Health Professor at VTT Technical Research Centre of Finland and the University of Oulu / Oulu Business School, the Martti Ahtisaari Institute, and the Faculty of Medicine. She works as a program leader and a collaborator between different units and departments in University of Oulu, VTT and other OuluHealth (ouluhealth.fi) ecosystem players. She currently focuses her research in the data-driven service co-creation and business models in health and wellbeing sectors. During 2010-2012, Minna worked as a Business Developer in the Institute Mines Telecom, Paris, and European Innovation Technology (EIT) network in Helsinki. Her key focus areas as a business developer have been in healthcare organizations and digital cities. Her research has been focused on the areas of software development, agile development, and service innovation.

Mari Ervasti is a Senior Scientist in the Wellness and Living team at VTT Technical Research Centre of Finland. She received her MSc in Information Networks from the University of Oulu in 2007, and her DSc (Tech) degree in Human-Centered Technology from the Tampere University of Technology in 2012. She has worked as a project manager and researcher in several multi-disciplinary research projects dealing with human-technology interaction, and has over 30 scientific publications in the field. Mari's research focuses on user experience design and evaluation in versatile application domains with a special focus on participatory design by utilizing user-driven methods. Furthermore, her research addresses the need for predicting and estimating the impacts and value of novel technologies for different stakeholders. Recently, she has focused on the co-creation of connected health services together with patients, healthcare professionals, and companies in the context of future digital hospitals.
Pia Hurmelinna-Laukkanen is a Professor of Marketing, especially relating to international business, in the Oulu Business School at the University of Oulu, Finland, and she is an Adjunct Professor (Knowledge Management) at the Lappeenranta University of Technology's School of Business and Management. She has published over 60 refereed articles in journals such as the Journal of Product Innovation Management, Industrial and Corporate Change, Industrial Marketing Management, $R \& D$ Management, and Technovation. She has contributed to book chapters, over 100 conference papers, and several other scientific and managerial publications. Most of her research has involved innovation management and appropriability issues, including examination of different knowledge protection and value capturing mechanisms. The research covers varying contexts such as internationalization and inter-organizational collaboration.

Satu Nätti is a Professor at the Oulu Business School in Finland. Her main research interests relate to innovation network orchestration, professional services, and key account management. She has published in such journals as Industrial Marketing Management, the Journal of Business and Industrial Marketing, the Journal of Service Management, the Journal of Services Marketing, and the Service Industries Journal.

\section{Acknowledgments}

This article was developed from a paper presented at the ISPIM Innovation Conference in Vienna, Austria, June 18-21, 2017. ISPIM (ispim-innovation.com) - the International Society for Professional Innovation Management - is a network of researchers, industrialists, consultants, and public bodies who share an interest in innovation management. 


\section{Orchestration Roles to Facilitate Networked Innovation in a Healthcare Ecosystem}

\section{Minna Pikkarainen, Mari Ervasti, Pia Hurmelinna-Laukkanen, and Satu Nätti}

\section{References}

Andersson, U., Blankenburg, H. D., \& Johansson, M. 2007. Moving or Doing? Knowledge Flow, Problem Solving, and Change in Industrial Networks. Journal of Business Research, 60(1): 32-40. https://doi.org/10.1016/j.jbusres.2006.09.010

Bate, P., \& Robert, G. 2006. Experience-Based Design: From Redesigning the System around the Patient to Co-Designing Services with the Patient. Quality and Safety in Healthcare, 15(5): 307-310.

https://doi.org/10.1136/qshc.2005.016527

Black, H. G., \& Gallan, A. S. 2015. Transformative Service Networks: Co-Created Value as Well-Being. The Service Industries Journal, 35(15-16): 826-845

http://dx.doi.org/10.1080/02642069.2015.1090978

Brown, J. S., \& Duguid, P. 2001. Knowledge and Organization: A Social-Practice Perspective. Organization Science, 12(2): 198-213. https://doi.org/10.1287/orsc.12.2.198.10116

Caulfield, B. M., \& Donnelly, S. C. 2013. What is Connected Health and Why It Will Change Your Practice. QJM: An International Journal of Medicine, 106(8): 703-707.

https://doi.org/10.1093/qjmed/hct114

Comacchio, A., Bonesso, S., \& Pizzi, C. 2012. Boundary Spanning between Industry and University: The Role of Technology Transfer Centres. Journal of Technology Transfer, 37: 943-966.

https://doi.org/10.1007/s10961-011-9227-6

Czakon, W., \& Klimas, P. 2014. Innovative Networks in KnowledgeIntensive Industries: How to Make Them Work? An Empirical Investigation into the Polish Aviation Valley. In D. Jemielniak (Ed.), The Laws of the Knowledge Workplace: Changing Roles and the Meaning of Work in Knowledge-intensive Environments: 133-139. Farnham, UK: Ashgate Publishing Ltd.

Dawson, B. K., Young, L., Tu, C., \& Chongyi, F. 2014. Co-Innovation in Networks of Resources - A Case Study in the Chinese Exhibition Industry. Industrial Marketing Management, 43(3): 496-503. https://doi.org/10.1016/j.indmarman.2013.12.017

Dhanaraj, C., \& Parkhe, A. 2006. Orchestrating Innovation Networks. Academy of Management Review, 31(3): 659-669. http://doi.org/10.5465/AMR.2006.21318923

Fichter, K. 2009. Innovation Communities: The Role of Networks of Promoters in Open Innovation. R\&D Management, 39: 357-371. http://dx.doi.org/10.1111/j.1467-9310.2009.00562.x

Frow, P., McColl-Kennery, J. R., \& Payne, A. 2016. Co-Creation Practices: Their Role in Shaping a Health Care Ecosystem. Industrial Marketing Management, 56: 24-39. https://doi.org/10.1016/j.indmarman.2016.03.007

Gawer, A., \& Cusumano, M. 2002. Platform Leadership. Cambridge, MA: Harvard Business School Press.

Gerwin, D. 2004. Coordinating New Product Development in Strategic Alliances. Academy of Management Review, 29(2): 241-257.

http://www.jstor.org/stable/20159031

Goduscheit, R. C. 2014. Innovation Promoters - A Multiple Case Study. Industrial Marketing Management, 43(3): 525-534. https://doi.org/10.1016/j.indmarman.2013.12.020
Grönroos C., \& Ravald, A. 2011. Service as Business Logic: Implications for Value Creation and Marketing. Journal of Service Management, 22(1): 5-22. https://doi.org/10.1108/09564231111106893

Hinterhuber, A. 2002. Value Chain Orchestration in Action and the Case of the Global Agrochemical Industry. Long Range Planning, 35(6): 615-635.

http://doi.org/10.1016/S0024-6301(02)00160-7

Howells, J. 2006. Intermediation and the Role of Intermediaries in Innovation. Research Policy, 35(5): 715-728. https://doi.org/10.1016/j.respol.2006.03.005

Hurmelinna-Laukkanen, P., \& Nätti, S. 2012. Network Orchestration for Knowledge Mobility - The Case of an International Innovation Community. Journal of Business Market Management, 5(4): 244-264.

Hurmelinna-Laukkanen, P., Nätti, S., \& Helin, S. 2014. Innovation Network Orchestrators - Distinction between Types and Roles. In Proceedings of 30th EGOS Colloquium, Rotterdam, The Netherlands, July 3-5, 2014.

Keeble, D., \& Wilkinson, F. 1999. Collective Learning and Knowledge Development in the Evolution of Regional Clusters of High Technology SMEs in Europe. Regional Studies, 33(4): 295-303. http://dx.doi.org/10.1080/00343409950081167

Kirkels, Y., \& Duysters, G. 2010. Brokerage in SME Networks. Research Policy, 39(3): 375-385. http://dx.doi.org/10.1016/j.respol.2010.01.005

Kovács, G., \& Spens, K. M. 2005. Abductive Reasoning in Logistics Research. International. Journal of Physical Distribution and Logistics Management, 35(2): 132-144. https://doi.org/10.1108/09600030510590318

Landsperger, J., Spieth, P., \& Heidenreich, S. 2012. How Network Managers Contribute to Innovation Network Performance. International Journal of Innovation Management, 16: 1240009. https://doi.org/10.1142/S1363919612400099

Lazar, J., Feng, J. H., \& Hochheiser, H. 2010. Research Methods in Human-Computer Interaction. Glasgow, Scotland: John Wiley \& Sons Ltd.

Leten, B., Vanhaverbeke, W., Roijakkers, N., Clerix, A., \& Van Helleputte, J. 2013. IP Models to Orchestrate Innovation Ecosystems: IMEC, A Public Research Institute in NanoElectronics. California Management Review, 55: 51-64.

Metcalfe, A. S. 2010. Examining the Trilateral Networks of the Triple Helix: Intermediating Organizations and Academy-IndustryGovernment Relations. Critical Sociology, 36: 503-519. https://doi.org/10.1177/0896920510365920

Möller, K. 2010. Sense-Making and Agenda Construction in Emerging Business Networks-How to Direct Radical Innovation. Industrial Marketing Management, 39(3): 361-371. https://doi.org/10.1016/j.indmarman.2009.03.014

Möller K., \& Rajala A. 2007. Rise of Strategic Nets - New Modes of Value Creation. Industrial Marketing Management, 36(7): 895-908. http://doi.org/10.1016/j.indmarman.2007.05.016

Nambisan S., \& Sawhney, M. 2011. Orchestration Processes in Network-Centric Innovation: Evidence From the Field. Academy of Management Perspectives, 25: 40-57. 


\section{Orchestration Roles to Facilitate Networked Innovation in a Healthcare Ecosystem \\ Minna Pikkarainen, Mari Ervasti, Pia Hurmelinna-Laukkanen, and Satu Nätti}

Napier, G., Rouvinen, P., Johansson, D., Finnbjörnsson, T., Solberg, E., \& Pedersen, K. 2012. The Nordic Growth Entrepreneurship Review 2012 NGER. Nordic Innovation Publication 2012:25 Final Report. Oslo, Norway: Nordic Innovation.

Roijakkers, N., Leten, B., Vanhaverbeke, W., Clerix, A., \& Van Helleputte, J. 2013. Orchestrating Innovation Ecosystems_IMEC. In Proceedings of the 35th DRUID Conference 2013, Barcelona, Spain, June 17-19, 2013.

Swan, J., \& Scarbrough, H. 2005. The Politics of Networked Innovation. Human Relations, 58(7): 913-943. https://doi.org/10.1177/0018726705057811

Tsujimoto, M., Kajikawa, Y., Tomita, J., \& Matsumoto, Y. 2017. A Review of the Ecosystem Concept-Towards Coherent Ecosystem Design. Technological Forecasting and Social Change (In press). https://doi.org/10.1016/j.techfore.2017.06.032

Vargo, S. L., \& Lusch, R. F. 2004. Evolving to a New Dominant Logic for Marketing. Journal of Marketing, 68(1): 1-17. https://doi.org/10.1509/jmkg.68.1.1.24036

Valkokari, K., Paasi, J., Luoma, T., \& Leen, N. 2009. Beyond Open Innovation - The Concept of Networked Innovation. In Proceedings of the 2nd ISPIM Innovation Symposium, Stimulating Recovery - The Role of Innovation Management. International Society for Professional Innovation Management (ISPIM), New York, December 6-9, 2009.

Wallin, J. 2006. Business Orchestration: Strategic Leadership in the Era of Digital Convergence. Chichester, UK: Wiley \& Sons.

Yin, R. 2003. Case Study Research: Design and Methods (3rd Ed.). Thousand Oaks, CA: Sage Publications.

Welborn, R., \& Kasten, V. 2003. The Jericho Principle: How Companies Use Strategic Collaboration to Find New Sources of Value. Hoboken, NJ: Wiley.

Wilkinson, I., \& Young, L. 2002. On Cooperating: Firms, Relations, Network. Journal of Business Research, 55(2): 123-132. https://doi.org/10.1016/S0148-2963(00)00147-8

Wenger, E. C., McDermott, R., \& Snyder, W. M. 2002. Cultivating Communities of Practice: A Guide to Managing Knowledge. Cambridge, MA: Harvard Business School Press.

Citation: Pikkarainen, M., Ervasti, M., Hurmelinna-

Laukkanen, P., \& Nätti, S. 2017. Orchestration Roles to

Facilitate Networked Innovation in a Healthcare

Ecosystem. Technology Innovation Management Review,

7(9): 30-43. http://doi.org/10.22215/timreview/1104

Keywords: innovation orchestration, healthcare ecosystem, roles, exploratory approach, high-level experts, case study 